\title{
Coordination of tRNA transcription with export at nuclear pore complexes in budding yeast
}

\author{
Miao Chen ${ }^{1}$ and Marc R. Gartenberg ${ }^{1,2,3}$ \\ ${ }^{1}$ Department of Biochemistry and Molecular Biology, Robert Wood Johnson Medical School, Rutgers University, Piscataway, \\ New Jersey 08854, USA; ${ }^{2}$ The Cancer Institute of New Jersey, New Brunswick, New Jersey 08901, USA
}

tRNAs are encoded by RNA polymerase III-transcribed genes that reside at seemingly random intervals along the chromosomes of budding yeast. Existing evidence suggests that the genes congregate together at the nucleolus and/or centromeres. In this study, we re-examined spatial and temporal aspects of tRNA gene $(t D N A)$ expression. We show that $t D N A$ transcription fluctuates during cell cycle progression. In $M$ phase, when tRNA synthesis peaks, $t D N A$ s localize at nuclear pore complexes (NPCs). Docking of a $t D N A$ requires the DNA sequence of the contacted gene, nucleoporins Nup60 and Nup2, and cohesin. Characterization of mutants that block NPC localization revealed that docking is a consequence of elevated $t D N A$ transcription. NPC- $t D N A$ contact falters in the absence of the principal exportin of nascent tRNA, Los1, and genetic assays indicate that gating of $t D N A s$ at NPCs favors cytoplasmic accumulation of functional tRNA. Collectively, the data suggest that $t D N A s$ associate with NPCs to coordinate RNA polymerase III transcription with the nuclear export of pre-tRNA. The M-phase specificity of NPC contact reflects a regulatory mechanism that may have evolved, in part, to avoid collisions between DNA replication forks and transcribing RNA polymerase III machinery at NPCs.

[Keywords: tRNA gene; RNA polymerase III; nuclear pore complex; cohesin; cell cycle; Los1 exportin]

Supplemental material is available for this article.

Received December 18, 2013; revised version accepted March 19, 2014.

Nuclear pore complexes (NPCs) form large aqueous channels through the nuclear envelope that permit transfer of materials between the nucleus and cytoplasm. In 1985, Blobel (1985) proposed the gene-gating hypothesis, which stipulated that transcriptionally poised genes associate with NPCs. In this way, tethered genes would be situated to export transcripts directly to the cytoplasm. The original gene-gating scheme also envisioned that genome packaging would influence the distribution of NPCs on the nuclear envelope. A contemporary spin on this idea posits that anchorage of genes to NPCs and other structures at the edge of the nucleus orchestrates the three-dimensional structure of the genome (Taddei and Gasser 2012).

Substantial evidence for gating of RNA polymerase II genes has been obtained primarily from studies of the budding yeast Saccharomyces cerevisiae. Genome-wide approaches revealed that components of the NPC, known as nucleoporins or Nups, associate with many active genes (Casolari et al. 2004; Schmid et al. 2006). Focused analyses of representative examples showed that the

${ }^{3}$ Corresponding author

E-mail marc.gartenberg@rutgers.edu

Article is online at http://www.genesdev.org/cgi/doi/10.1101/gad.236729.113. genes moved from the nucleoplasm to the nuclear periphery upon induction in a Nup-dependent manner. That transcription and export might be coupled events emerged from studies showing that mRNA export machinery associated with transcribed genes and that the machinery was required for positioning the genes at NPCs (for review, see Dieppois and Stutz 2010). Whether gating of genes at NPCs affects their expression has been less certain. For example, one study showed that artificially targeting a reporter gene to NPCs increased transcriptional output (Menon et al. 2005). A different study, however, found that the level of expression of a prototypical inducible gene was unaffected by mutations that displaced the gene from NPCs (Cabal et al. 2006). Experiments like these and others made it clear that gating of RNA polymerase II genes is not essential for their expression. Instead, recent work suggests that the process fine-tunes expression kinetics by altering the rates of

(C) 2014 Chen and Gartenberg This article is distributed exclusively by Cold Spring Harbor Laboratory Press for the first six months after the fullissue publication date (see http://genesdev.cshlp.org/site/misc/terms.xhtml). After six months, it is available under a Creative Commons License (Attribution-NonCommercial 4.0 International), as described at http:// creativecommons.org/licenses/by-nc/4.0/. 
initial transcriptional induction as well as transcriptional reactivation (Hampsey et al. 2011; Texari et al. 2013).

Gating of active genes at NPCs is not strictly conserved. In mice and humans, for example, a number of developmentally regulated genes move away from the nuclear periphery upon induction, producing mRNA protein complexes that travel through the nucleoplasm to NPCs before export (see references in Egecioglu and Brickner 2011; Oeffinger and Zenklusen 2012). Nevertheless, components of the nuclear pore may still play significant roles in transcription. Recent work in Drosophila showed that several Nups migrate from NPCs to the nuclear interior, where they bind to and promote expression of some RNA polymerase II genes and repress the expression of others (Capelson et al. 2010; Kalverda et al. 2010).

RNA polymerase III transcribes small conserved noncoding RNAs, including 274 tRNA genes (termed $t D N A$ s) that are scattered among the chromosomes of yeast. Despite the broad genomic distribution, $t D N A$ s often congregate at or near the nucleolus, where ribosomal RNA is synthesized and assembled into ribosomes (Thompson et al. 2003). Cocompartmentalization, it was argued, might favor coordinated control of both tRNA and ribosome biogenesis (Haeusler and Engelke 2006). Indeed, tRNA synthesis and early processing are thought to occur at the nucleolus (Bertrand et al. 1998). Mutations that attenuate expression of mature ribosomal RNA disperse tDNAs from that location (Thompson et al. 2003).

Cohesin, the protein complex that holds sister chromatids together, was recently shown to also participate in nucleolar events. In mutants that disrupt cohesin activation and utilization, ribosomal RNA production decreases, and $t D N A$ clustering is lost (Gard et al. 2009; Bose et al. 2012). Cohesin is intimately associated with the genes involved. Specifically, the complex binds the array of ribosomal RNA genes (the rDNA), where it suppresses unequal sister chromatid exchange (Kobayashi et al. 2004). The complex also loads onto chromosomal arms at $t D N A \mathrm{~s}$ (D'Ambrosio et al. 2008).

The yeast $t D N A$ named $t T(A G U) C$ has received substantial attention because of its immediate proximity to $H M R$, a paradigmatic heterochromatic locus. The gene creates a barrier to propagation of heterochromatin from $H M R$ into adjacent euchromatic domains by a mechanism involving chromatin modification (Kirkland et al. 2013). Barrier function also requires cohesin, which loads onto chromatin at $t T(A G U) C$ to create heterochromatindependent cohesion at HMR (Donze et al. 1999; Dubey and Gartenberg 2007). Paradoxically, fluorescence microscopy studies showed that $t T(A G U) C$ localized to the nucleolus infrequently even though the gene is transcribed (Donze and Kamakaka 2001; Valenzuela et al. 2008). Evidence that $t T(A G U) C$ instead associates with NPCs emerged with the discovery that Nups bind the $t D N A$ and direct the gene to the nuclear periphery (Ruben et al. 2011). In this study, we show that NPC tethering is a general feature of yeast $t D N A$ s that occurs in $\mathrm{M}$ phase when transcription of the genes elevates. Gating of the genes at NPCs requires the dedicated tRNA exportin
Los1, suggesting that $t D N A$ transcription is coordinated with nuclear export of nascent tRNA.

\section{Results}

tDNAs associate with NPCs in M phase

Based on preliminary studies of $t T(A G U) C$ localization, we speculated that the gene and other $t D N A$ s associate with NPCs at the nuclear envelope. This idea was tested by tagging chromosomal domains bearing $t D N A s$ with lac operator arrays $\left(1 a c^{o p}\right)$ in cells expressing GFP-tagged lac repressor and Nup Nic96 tagged with mRFP. $t D N A s$ $t T(A G U) C$ and $t S(C G A) C$ on chromosome III were evaluated as well as $t T(U G U) G 1$ on chromosome VII. The strains also contained the nup133- $\Delta N$ mutation, which causes NPCs to aggregate on the nuclear membrane without disrupting protein import or polyA ${ }^{+}$RNA export significantly (Doye et al. 1994). In nup133- $\Delta N$ cells, Nic96-mRFP coalesced into one to three red foci instead of forming a ring of red fluorescence at the nuclear rim (Fig. 1A). With these tools, association of specific chromosomal domains with NPCs could be distinguished from other forms of perinuclear enrichment (Taddei and Gasser 2012).

Colocalization, defined as adjacent or overlapping $t D N A$ and NPC foci, was scored in asynchronously grown cultures, with each cell categorized morphologically as being in the G1, S, or M phases of the cell cycle (see the Materials and Methods for detailed criteria). Cells with segregating chromosomes in anaphase were excluded from the analysis. Strikingly, all three $t D N A$ s localized at NPCs more frequently in M phase than in either G1 or $S$ phase (Fig. 1B). In the case of $t T(A G U) C$, colocalization occurred in $50 \%$ of M-phase cells yet in only $30 \%$ of cells in either G1 or S. As a control, the nuclear position of a chromosomal domain that lacks $t D N A$ s was scored by the same criteria. We used the highly mobile chromosomal domain containing LYS2, referred to here as the lys2 domain (Gartenberg et al. 2004). This $t D N A$-free region localized at NPCs in only $30 \%$ of cells irrespective of whether they were in G1, S, or M phase. Similarly, the tDNAs and lys2 colocalized with a nucleolar marker (Nop1) infrequently and in a cell cycle-independent manner (Fig. 1C). In fact, $t D N A-N o p 1$ colocalization occurred less frequently than lys2-Nop1 colocalization. These results indicate that chromosomal domains bearing $t D N A \mathrm{~s}$ associate with NPCs more frequently in or near M phase than during other phases of the cell cycle.

Localization studies were repeated for $t T(A G U) C$ in cells arrested at anaphase onset by depletion of Cdc20, a component of the anaphase-promoting complex (see the Materials and Methods). Here, too, positioning of the domain at NPCs was significantly greater than the lys2 control, although the absolute levels of colocalization of both loci were dampened (Fig. 1D). In contrast, M-phase arrest by exposure to the microtubule inhibitor nocodazole abolished the localization of the $t D N A$ at NPCs. Previously, colocalization of $t D N A$ clusters with the nucleolus was blocked by nocodazole (Haeusler et al. 2008). 
A.

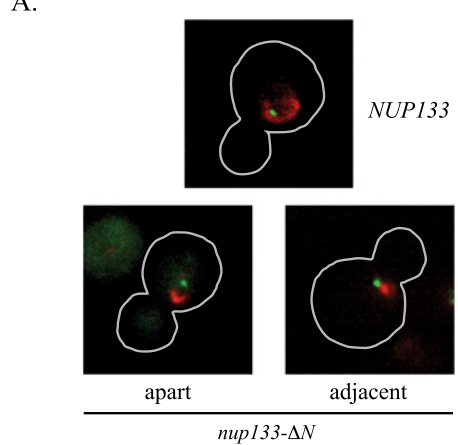

D.

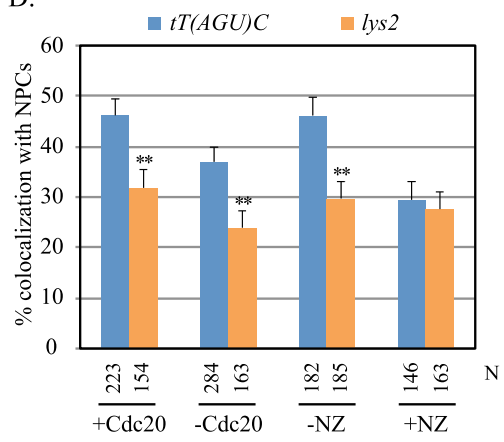

B.

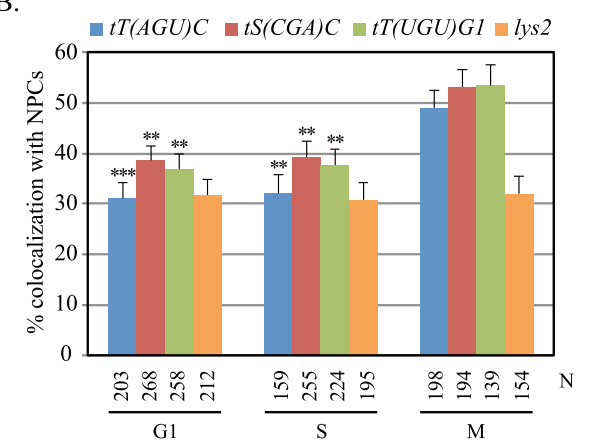

C.

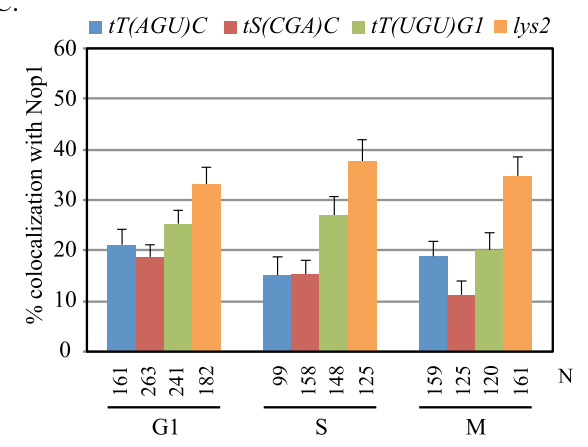

Figure 1. Localization of $t D N A$ s at NPCs. (A) Representative images of cells from asynchronously grown cultures. GFP-lac repressor (green) and Nic96-mRFP (red) are shown in nup133- $\Delta N$ and NUP133 cells, outlined in gray. (B) tDNA localization at NPCs. Asynchronously grown cultures of strains MC78 $\left[t T(A G U) C:: 2561 a c^{o p}\right], \quad M C 197[t S(C G A) C::$ $\left.2561 a c^{o p}\right], \mathrm{MC} 198\left[t T(U G U) G 1:: 2561 a c^{o p}\right]$, and MC180 (lys2::2561ac ${ }^{o p}$ ) were used. $N$ equals the number of cells examined. Localization of each $t D N A$ at NPCs was significantly higher in $M$ phase than in G1 or S. Pairwise $\chi^{2}$-tests, $\left(^{\star \star \star}\right)<5 \times 10^{-4} ;\left(^{\star \star}\right)<5 \times$ $10^{-3}$. (C) $t D N A$ s colocalized with the nucleolus rarely. Strains MC250 [tT(AGU)C:: $\left.2561 a c^{o p}\right]$, MC247 [tS(CGA)C::2561ac $\left.{ }^{o p}\right]$, MC248 [tT(UGU)G1::2561ac $\left.{ }^{\circ p}\right]$, and MC249 (lys2::256lac $\left.{ }^{o p}\right)$ bearing a Nop1-CFP expression plasmid (pJW1327) were examined in asynchronous cultures. The specific $t D N A s$ examined here differ from those described in Thompson et al. (2003). (D) NPC-tT(AGU)C colocalization in $\mathrm{M}$ phase. Strains MC78 $\left[t T(A G U) C:: 2561 a c^{o p}\right]$ and MC180 (lys2:: $\left.2561 a c^{o p}\right)$ bearing MET3p-CDC20 were examined before and after depletion of Cdc20. Strains MC64 [tT(AGU)C::2561ac $\left.{ }^{\text {op }}\right]$ and MC226 (lys2::256lac $\left.{ }^{o p}\right)$ were examined before and after addition of nocodazole (NZ). In the absence of either arrest, only M-phase cells were scored. NPC localization was significantly higher for $t T(A G U) C$ than lys2 where noted.

Collectively, these findings implicate microtubules and/or the spindle checkpoint pathway in controlling $t D N A$ positioning. Based on these results, Cdc20 depletion was used to obtain M-phase-arrested cells for most subsequent experiments.

\section{Nups tether tDNAs to NPCs in M phase}

Nup60 is a fixed component of the NPC, binding stably to the nuclear basket that projects into the nucleoplasm. Nup2, in contrast, is a mobile factor that associates with the nuclear basket transiently by binding Nup60 (Denning et al. 2001; Dilworth et al. 2005). Both proteins cross-link efficiently to $t T(A G U) C$ but not to other landmarks of the $t T(A G U) C$ chromosomal domain, like $H M R$ (Ruben et al. 2011). Both proteins also associate with RNA polymerase II genes and have been implicated in repositioning the genes at NPCs upon transcriptional induction (Casolari et al. 2004; Schmid et al. 2006). Figure $2 \mathrm{~A}$ shows that in $\mathrm{M}$ phase-arrested cells, deletion of NUP2 or NUP60 reduced localization of $t T(A G U) C$ at NPCs to the level of the $t D N A$-free lys2 control. In other phases of the cell cycle, NPC localization was unaffected by the mutations (Supplemental Fig. S1; data not shown). Deletion of $t T(A G U) C$ reduced NPC localization of the GFP-tagged chromosomal domain to a level comparable with those seen in the Nup mutants. Collectively, the results indicate that NUP2 and NUP60 are required for docking $t T(A G U) C$ at NPCs.

If $t D N A$ association with NPCs oscillates during the cell cycle, then binding of Nups to the genes should also vary with cell cycle phase. Chromatin immunoprecipitation (ChIP) followed by quantitative PCR (ChIP-qPCR) was used to evaluate binding of TAP-tagged Nup60 at the three $t D N A s$ described in Figure 1. Experiments were performed in cells arrested in $M$ phase by Cdc20 depletion or in G1 by exposure to the $\alpha$-factor mating pheromone. Values were normalized to the GIT1 promoter, where Nup60 binds negligibly (Ruben et al. 2011). Figure 2B shows that all three $t D N A$ s cross-linked efficiently to Nup60 in M-phase-arrested cells but not in G1-arrested cells. Nup2 was required for the enhanced binding of Nup60 in M phase, suggesting that the mobile Nup mediates contact between $t D N A$ s and NPCs. In this set of experiments, Nup60 binding was also measured at ETC4. ETC sites bind transcription factor TFIIIC but not the rest of the RNA polymerase III transcriptional machinery (for review, see Kirkland et al. 2013). Notably, ETC sites contribute to genome organization in both S. cerevisiae and Schizosaccharomyces pombe by tethering chromosomal domains at the nuclear periphery (Noma et al. 2006; Hiraga et al. 2012). Figure 2B shows that Nup60 did not associate with ETC4 in either M or G1. Taken together, these experiments show that $t D N A$ s but not ETC sites associate with an integral feature of NPCs in a Nup2dependent manner during $M$ phase. The data support and extend the microscopy results in Figure 1 with an independent set of strains that lack artificially clustered NPCs.

To determine whether other sequences on chromosome III contribute to $t T(A G U) C$ positioning, the chro- 
A.

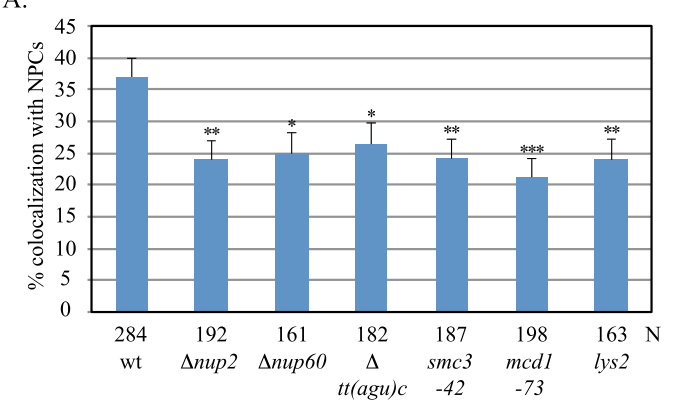

B.

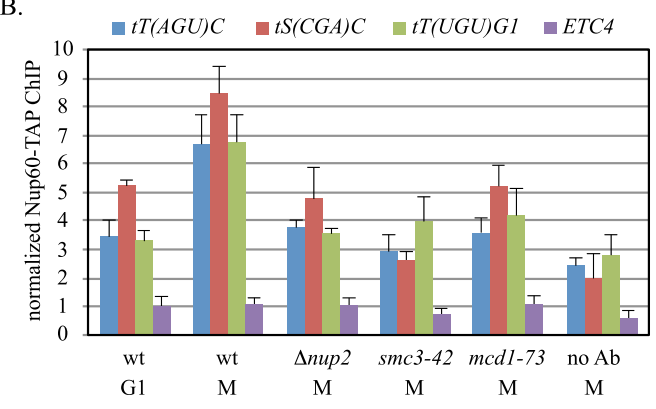

C.
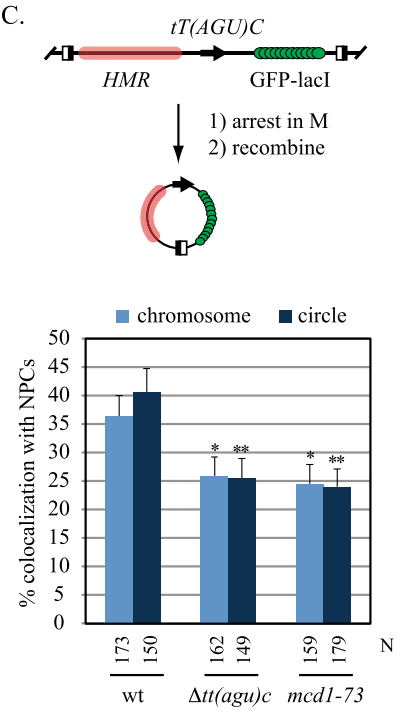

Figure 2. Requirements for NPC- $t T(A G U) C$ contact. (A) Localization of $t T(A G U) C$ in mutants. Strains MC78 (wt), MC210 (\$nup2),

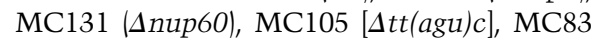
(smc3-42), MC82 (mcd1-73), and MC180 $\left(1 y s 2:: 2561 a c^{o p}\right)$ were evaluated after Cdc20 depletion. NPC colocalization was significantly lower in mutants. Pairwise $\chi^{2}$-tests, $\left({ }^{\star \star \star}\right)<5 \times 10^{-4} ;\left(^{\star \star}\right)<5 \times 10^{-3} ;\left(^{\star}\right)<5 \times 10^{-2}$. (B) Nup60 occupancy at $t D N A$ s. ChIP-qPCR of Nup60-TAP was performed with strains MC177 (wt), MC207 (Anup2), MC178 (smc342), and MC179 (mcd1-73) after arrest in G1 or M phase. (No Ab) No TAP antibody. Nup60 was enriched at $t D N A$ s significantly during M-phase arrest in the wild-type strain but not in mutants $(P$-values in Supplemental Table S4). (C) Localization of extrachromosomal $t T(A G U) C$. The half-filled boxes of the diagram represent recombinase target sites that were used to form DNA circles inducibly after arrest in M phase (Dubey and Gartenberg 2007). mosomal domain bearing the $t D N A$ spanning $\sim 7 \mathrm{~kb}$ from $H M R$ to GIT1 was excised from the chromosome and ligated into a circle by inducible site-specific recombination (Fig. 2C; Dubey and Gartenberg 2007). The excision product was enriched at NPCs in M-phase-arrested cells but not when $t T(A G U) C$ was deleted. These data indicate that positioning of $t T(A G U) C$ at NPCs does not require cis-linkage to neighboring domains, like telomeres, which anchor chromosomes to the nuclear membrane (Taddei and Gasser 2012).

The ability of yeast heterochromatin to sequester repressed domains at the nuclear periphery prompted us to evaluate NPC-tDNA contact in mutants that block heterochromatin assembly (Taddei and Gasser 2012). Localization of $t T(A G U) C$ at NPCs was reduced somewhat but not by a measure that was statistically significant (Supplemental Fig. S2). In agreement, binding of Nup60 at $t T(A G U) C$ was not found to be heterochromatin-dependent (Ruben et al. 2011). We conclude that the $t D N A$ is the dominant factor that positions the $t T(A G U) C$ chromosomal domain at NPCs in M phase.

\section{NPC-tDNA contact requires cohesin}

The numerous links between $t D N A$ s and cohesin led us to test whether the complex plays a role in NPC- $t D N A$ contact. To this end, the microscopy and ChIP-qPCR assays described above were repeated in conditional mutants of cohesin subunits Smc3 and Mcd1. The strains were cultured at $30^{\circ} \mathrm{C}$, an intermediate temperature that leads to nonlethal defects in sister chromatid cohesion during mitotic growth (data not shown). Strikingly, localization of $t T(A G U) C$ at clustered NPCs dropped below $25 \%$ in both M-phase-arrested mutants (Fig. 2A). Similar results were obtained when the $t T(A G U) C$ domain was uncoupled from the chromosome by recombination
(Fig. 2C). Correspondingly, ChIP-qPCR experiments with TAP-tagged Nup60 showed that binding of the Nup to representative $t D N A$ s required cohesin (Fig. 2B). Together, these findings define an additional role for cohesin in the behavior of $t D N A \mathrm{~s}$ in yeast. With regard to NPC tethering, we do not know whether cohesin acts directly at $t D N A$ s or the complex influences $t D N A$ s indirectly through actions within the nucleolus or elsewhere (Gard et al. 2009; Bose et al. 2012). Either way, the ability to disrupt $t D N A$ positioning with these mutants provides a tool to probe the causes and consequences of NPCtDNA contact.

\section{Nascent tRNA increases when tDNAs associate with NPCs}

Based on the precedent of activated RNA polymerase II genes associating with NPCs, we hypothesized that localization of $t D N A$ s at NPCs was related to their transcription. To examine this possibility, ChIP-qPCR was used to measure the binding of RNA polymerase III to representative $t D N A$ s. A TAP tag was appended to Rpc25, an RNA polymerase III subunit not found in either RNA polymerase I or II, and ChIP-qPCR was performed as described above. Figure 3A shows that binding of Rpc25 to all three $t D N A$ s was greater during $M$-phase arrest than during $\mathrm{G} 1$ arrest. Nonetheless, binding in G1 cells was higher than the no antibody control, suggesting that some transcription persists when $t D N A$ s are not at NPCs. No binding was recorded at ETC4. We conclude that RNA polymerase III occupancy on $t D N A$ s increases when the genes associate with NPCs in M phase.

To determine whether the levels of nascent tRNA transcripts fluctuate during the cell cycle, we measured the appearance of select short-lived, intron-bearing pretRNAs. Our analysis focused on (1) tRNA ${ }^{\operatorname{Trp}}(\mathrm{CCA})$ and 
A.

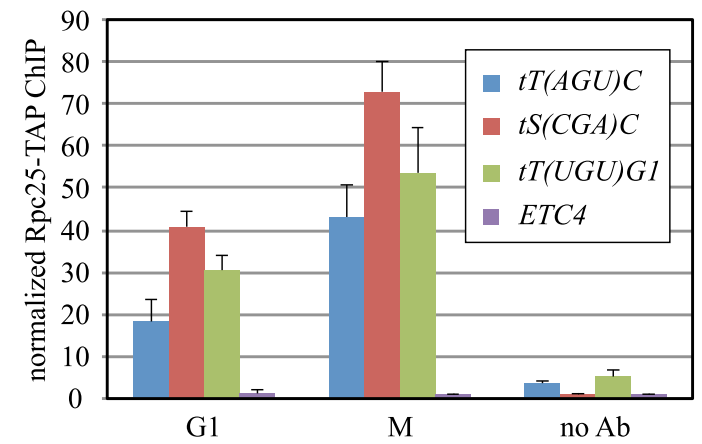

C.

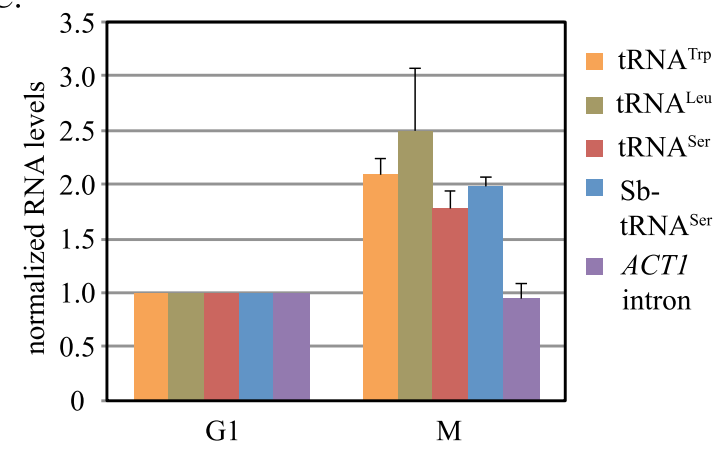

B.

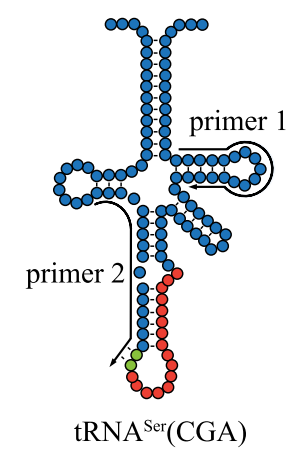

D.

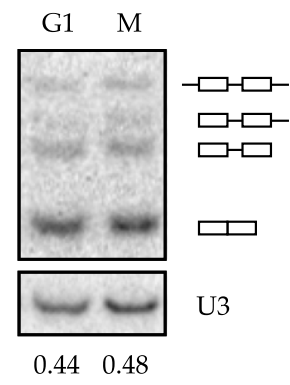

Figure 3. tRNA synthesis during the cell cycle. (A) Rpc25 occupancy at $t D N A$ s. ChIPqPCR of Rpc25-TAP was performed with strain MC195 arrested in M phase or G1. Rpc25 binding at $t D N A$ s was enriched significantly during $\mathrm{M}$-phase arrest $(P$-values are in Supplemental Table S4). (B) Pre-tRNA ${ }^{\mathrm{Ser}}$ (CGA) of $S$. cerevisiae and $S$. bayanus. Red circles represent the conserved intronic nucleotides, and green circles represent intronic nucleotide polymorphisms. Primers for RT (primer 1) and qPCR (primers 1 and 2) are shown. $(C)$ Nascent tRNA levels. RT-qPCR was performed with strain MC204 [ $\Delta t t(a g u) c:: S b-t S(C G A) C]$. tRNA levels were significantly higher in $M$ phase $(P$-values are in Supplemental Table S4). (D) Northern blot analysis of tRNA precursors and products. Radiolabeled oligonucleotide probes were hybridized to unspliced and spliced tRNA ${ }^{\mathrm{Ser}}(\mathrm{CGA})$, albeit with different affinities, in extracts of strain MC172. Unprocessed, 5' processed, end processed, and mature species are labeled graphically. The ratio of end processed/spliced species is indicated below each lane.
tRNA $^{\text {Leu }}(\mathrm{CAA})$, which are encoded by families of six and 10 yeast $t D N A s$, respectively, and (2) $\mathrm{tRNA}^{\mathrm{Ser}}(\mathrm{CGA})$ encoded by either the single yeast gene $t S(C G A) C$ described above or an orthologous gene from Saccharomyces bayanus that we integrated in place of the intron-free $t T(A G U) C$. In preliminary studies, we verified that the ectopic $S$. bayanus gene [referred to here as $S b-t S(C G A) C$ ] complimented deletion of the essential $t S(C G A) C$ gene, demonstrating that it produced functional tRNA ${ }^{\mathrm{Ser}}$ (CGA) in S. cerevisiae (Supplemental Fig. S3). Unspliced transcripts from the two genes can be distinguished from one another by a dinucleotide polymorphism within their introns (Fig. 3B; Supplemental Fig. S3). Pre-tRNA levels were measured by reverse transcription (RT) followed by qPCR (RT-qPCR) and normalized to mature ACT1 mRNA. We found that the levels of the four representative pre-tRNAs were roughly twofold higher in cells arrested in $M$ phase than in cells arrested in G1 (Fig. $3 \mathrm{C})$. In contrast, the level of nascent ACT1 mRNA, which also bears an intron, did not vary between the two cell cycle arrests. These findings indicate that the levels of unspliced pre-tRNAs rise in $\mathrm{M}$ phase when $t D N A s$ associate more frequently with RNA polymerase III and NPCs.

If $t D N A$ transcription during $M$ phase exceeds the capacity of some subsequent step in tRNA biogenesis, such as splicing, then the levels of pre-tRNA measured in Figure 3C might reflect diminished maturation instead of increased production. In yeast, pre-tRNA splicing occurs on the cytoplasmic surface of the mitochondria (Yoshihisa et al. 2003). Failure to export nascent tRNA during Mphase arrest could result in an abnormal accumulation of unspliced intermediates. To determine whether pretRNA levels rise disproportionately relative to the mature tRNA pool, we measured the distribution of processing intermediates of the endogenous tRNA ${ }^{\mathrm{Ser}}$ (CGA) by Northern blot analysis. The U3 snoRNA served as an RNA polymerase II-generated loading control. Figure 3D shows that the ratio of precursor to mature tRNA ${ }^{\mathrm{Ser}}$ (CGA) is equivalent in both $M$ - and G1-arrested cultures. We conclude that the increase in pre-tRNA level in M phase when $t D N A$ s associate with NPCs is the consequence of increased transcription, not decreased maturation. Curiously, the cell cycle oscillations of tRNA synthesis in budding yeast contrasts those in fission yeast and mammals, where RNA polymerase III transcription drops during mitosis (Gottesfeld and Forbes 1997; Iwasaki et al. 2010).

\section{NPC contact is not required for tDNA transcription}

To determine whether association of $t D N A$ s with NPCs is the cause or consequence of transcription, we measured more precisely when pre-tRNA levels and Nup60 binding elevate during the cell cycle. To this end, cells were released from $\alpha$-factor arrest in G1, and aliquots of culture were harvested at timed intervals following the resumption of synchronous growth (Fig. 4A). RT-qPCR of RNA extracted from the cell pellets showed that levels of three different unspliced pre-tRNAs increased incrementally after release and peaked at $60 \mathrm{~min}$ when the cultures consisted entirely of cells with 2N DNA content (Fig. 4B). Pre-tRNA ${ }^{\operatorname{Trp}}(\mathrm{CCA})$ provides the most dramatic example, with a 2.5-fold rise from trough to peak. Using the same cell pellets, Nup60-TAP binding was evaluated by ChIP- 
A.

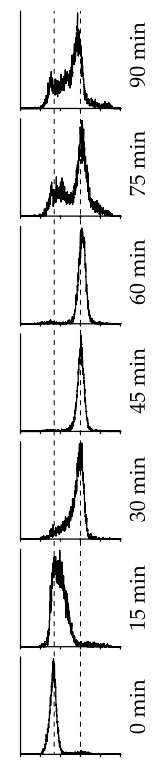

B

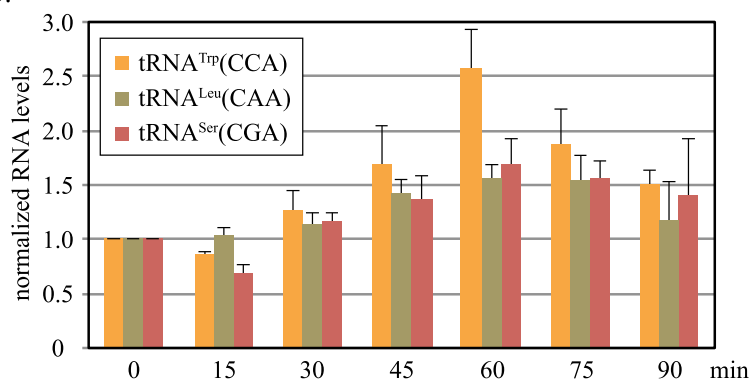

C.

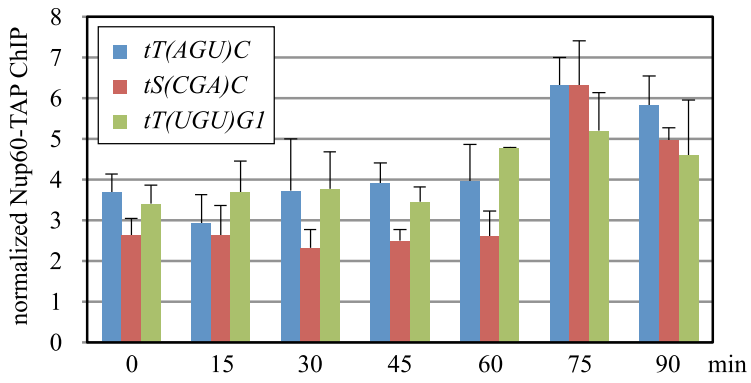

Figure 4. $t D N A$ transcription without NPC contact. (A) Flow cytometry of synchronized cell culture. Strain MC230 was released from $\alpha$-factor arrest at time 0. (B) Unspliced tRNA levels at 15-min intervals after release. Values at $60 \mathrm{~min}$ were significantly higher than those at time $0(P$-values are in Supplemental Table S4). (C) Levels of Nup60-TAP binding at representative $t D N A$ s at intervals after release. $(D)$ RNA polymerase III binding in mutants. ChIP-qPCR of Rpc25-TAP at the $t D N A$ s was performed in Cdc20depleted strains MC195 (wt), MC211 (Anup2), MC214 (smc3-42), and MC212 (mcd1-73). Rpc25 occupancy was not altered in these mutants.

D.

$\because t T(A G U) C \quad \square S(C G A) C \quad t T(U G U) G I$

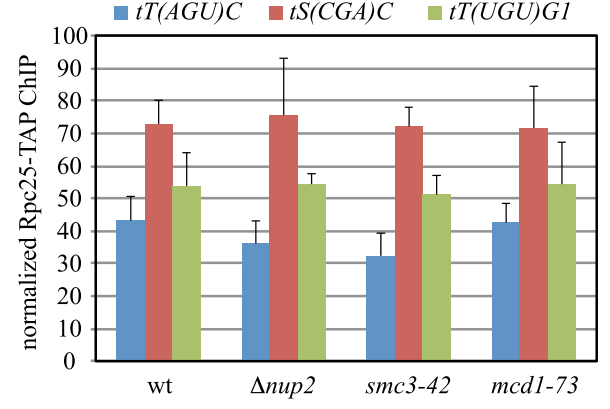

qPCR. Binding remained low and fairly constant at three select $t D N A$ s for $60 \mathrm{~min}$ after release (Fig. 4C). Strikingly, Nup60 binding rose sharply at $75 \mathrm{~min}$, the first time point measured following the peak in pre-tRNA levels. Based on the delay between pre-tRNA production and NPC binding, we infer that RNA polymerase III transcription increases first, and then $t D N A$ s migrate to NPCs.

If $t D N A$ transcription precedes NPC- $t D N A$ contact, then transcription of $t D N A$ s should persist in mutants that abolish contact. To test this notion, binding of Rpc25-TAP was measured under conditions that block association of $t D N A$ s with Nup60 and NPCs. The ChIPqPCR experiments in Figure 4D show that binding of the RNA polymerase III subunit to the $t D N A$ s in M-phasearrested cells persisted in strains either lacking Nup2 or bearing cohesin mutation $s m c 3-42$ or mcd1-73. These results indicate that NPC- $t D N A$ contact is not required for binding of RNA polymerase III to $t D N A$ s in $\mathrm{M}$ phase.

The use of synchronously growing cultures in the experiments of Figure 4, A-C, allays potential concerns about measuring nascent tRNA levels during cell cycle arrests. For example, Figure 4B showed that tRNA precursors accumulated as cells approached $M$ phase even when M-phase arrest by Cdc20 depletion was omitted from the protocol. Similarly, tRNA production dropped between successive $M$ phases in cells synchronized by transient Cdc20 depletion (Supplemental Fig. S4). This second result showed that nascent tRNA levels oscillated during cell cycle progression even in the absence of $\alpha$-factor arrest. The pheromone is a convenient tool but is known to trigger a host of physiological responses in yeast.

\section{Unrestricted RNA polymerase III transcription yields} $N P C-t D N A$ contact in $G 1$ and $S$

If transcription is a prerequisite for association of $t D N A s$ with NPCs, then conditions that elevate $t D N A$ transcription can be expected to increase NPC- $t D N A$ contact. This hypothesis was tested by deleting $M A F 1$, the central negative regulator of RNA polymerase III transcription (Boguta 2013). Upon exposure to stressors, such as nutrient deprivation or DNA damage, the protein is dephosphorylated, whereupon it interferes with binding of RNA polymerase III at $t D N A$ s. Even under relatively robust growth conditions, Maf1 exerts a measurable level of transcriptional inhibition (Roberts et al. 2006; Karkusiewicz et al. 2011).

ChIP-qPCR of the Rpc25 subunit was used to evaluate the influence of Maf1 on RNA polymerase III binding to representative $t D N A$ s. In Figure $5 \mathrm{~A}$, elimination of the regulator elevated levels of Rpc25 at all three genes. 
A.

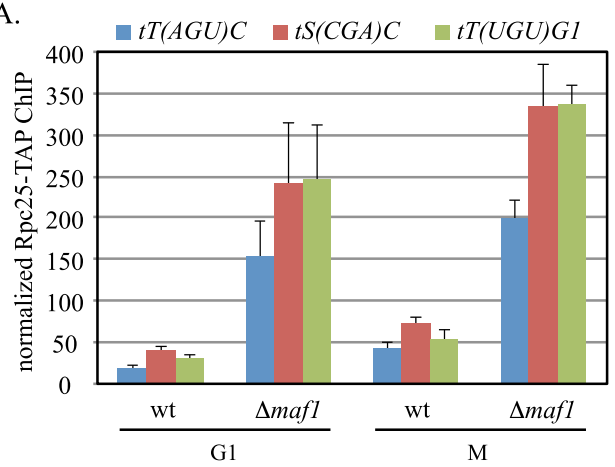

C.

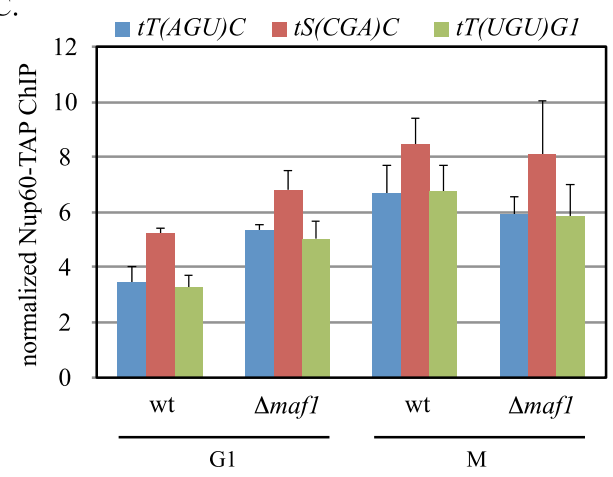

B.

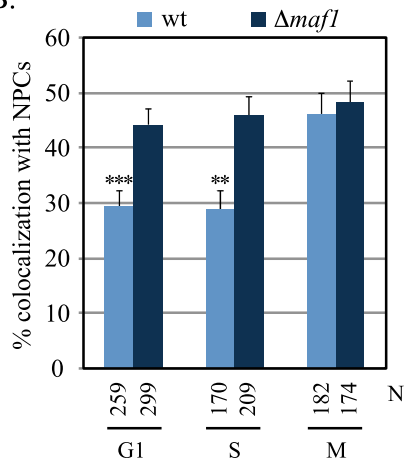

Figure 5. $t D N A$ transcription and NPC contact in the absence of MAF1. (A) Rpc25 occupancy. ChIP-qPCR of Rpc25-TAP at representative $t D N A$ s was evaluated during $M$ and G1 arrest in strains MC195 (wt) and MC217 (Amaf1). Rpc25 binding was enhanced significantly in the maf1-null ( $P$-values are in Supplemental Table S4). (B) Localization of $t T(A G U) C$ at NPCs. Asynchronous cultures

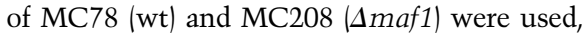
as in Figure 1, A and B. Colocalization was significantly higher in the maf1 strain in G1 and $S$ phase. Pairwise $\chi^{2}$-tests, $\left({ }^{\star \star \star}\right)<5 \times 10^{-4}$; $\left({ }^{\star \star}\right)<1 \times 10^{-3} .(C)$ Nup60 binding at $t D N A s$. ChIP-qPCR of Nup60-TAP was performed in strains MC177 (wt) and MC213 (Jmaf1) during arrest in $M$ or G1 phase. Nup60 binding was enriched significantly in the maf1 mutant in G1.
Notably, binding increased in both $\mathrm{M}$ - and G1-phasearrested cells. The results indicate that MAF1 attenuates $t D N A$ transcription even during the cell cycle arrests used in this study. Importantly, changes in RNA polymerase III activity were often accompanied by changes in NPC- $t D N A$ contact. Figure $5 \mathrm{~B}$ shows that localization of $t T(A G U) C$ at clustered NPCs increased in G1 and S phases to the level only seen in $M$ phase of wild-type cells. However, deletion of MAF1 did not enhance localization of $t D N A$ s with NPCs in M phase. In a complimentary approach, ChIP-qPCR was used to measure the influence of $M A F 1$ on the association of Nup60-TAP with $t D N A$ s. In agreement, deletion of the regulator yielded an increase in Nup60 binding only in G1 cells (Fig. 5C). During M-phase arrest, the level of bound Nup60 remained constant despite the increase in Rpc25 occupancy. The data are revealing in two ways. Foremost, they indicate that transcription by RNA polymerase III is limiting for NPC- $t D N A$ contact during G1 and S phase. At these stages, artificial stimulation of transcription increases tethering of $t D N A$ s at NPCs. Conversely, they indicate that NPC docking is maximal in M phase under the conditions tested. The data are consistent with NPCtDNA contact being limited by a factor other than transcription at this stage of the cell cycle.

$N P C-t D N A$ contact and the nuclear export of nascent tRNA

We reasoned that active $t D N A$ genes associate with NPCs to facilitate export of pre-tRNA from the nucleus. It is well established that tRNAs transit from the nucleus to the cytoplasm via a Ran-GTPase-mediated pathway
(Hopper 2013). Only recently has it become clear that tRNAs travel in both directions. Cytoplasmic tRNAs return to the nucleus by a constitutive process only to be re-exported (Shaheen and Hopper 2005; Takano et al. 2005). In yeast, Los1 is the principal exportin for introncontaining pre-tRNA (Hopper et al. 1980; Hellmuth et al. 1998; Sarkar and Hopper 1998; Murthi et al. 2010). Los1 is joined by a second exportin, Msn5, for the re-export of tRNAs (Shaheen and Hopper 2005; Takano et al. 2005). Msn5 contributes little to the export of intron-containing tRNA (Murthi et al. 2010). It is not certain whether the protein contributes to the initial export of intron-free tRNAs. Curiously, neither exportin is essential, and the double mutant is viable. These observations indicate that at least one additional route for tRNA export from the nucleus must exist.

To investigate whether tRNA export influences an upstream event like NPC-tDNA contact, we measured Nup60-TAP binding to $t D N A$ s in strains that lack either LOS1 or MSN5. Figure 6A shows that deletion of LOS1 hindered association of Nup60 with three representative $t D N A s$, including one with an intron $[t S(C G A) C]$ and two without introns [tT(AGU)C and $t T(U G U) G 1]$. In contrast, deletion of MSN5 did not alter binding of Nup60 to any of the $t D N A$ s evaluated in this study (Fig. 6A). We surmise that Los1 alone couples transcribing $t D N A$ s to NPCs irrespective of whether the genes contain or lack introns.

If Los 1 is required for NPC- $t D N A$ contact and contact is maximal in $M$ phase (Fig. $5 B, C$ ), then native levels of the protein might be a limiting factor in positioning transcribed $t D N A$ s at NPCs. To test whether NPC- $t D N A$ 
A.

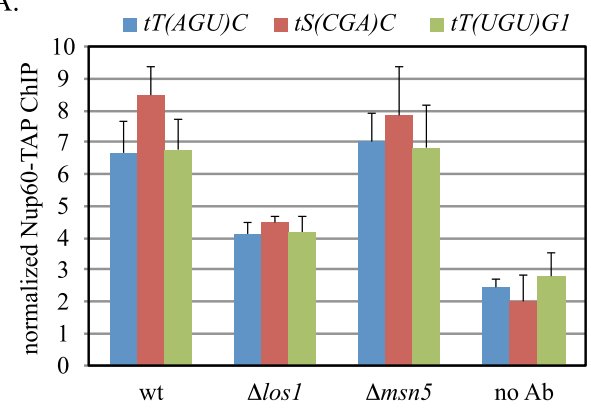

C.

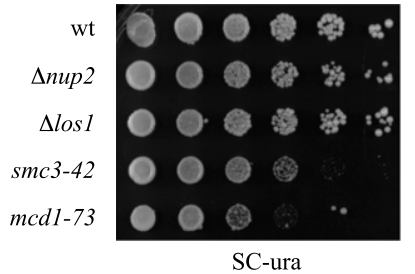

B.
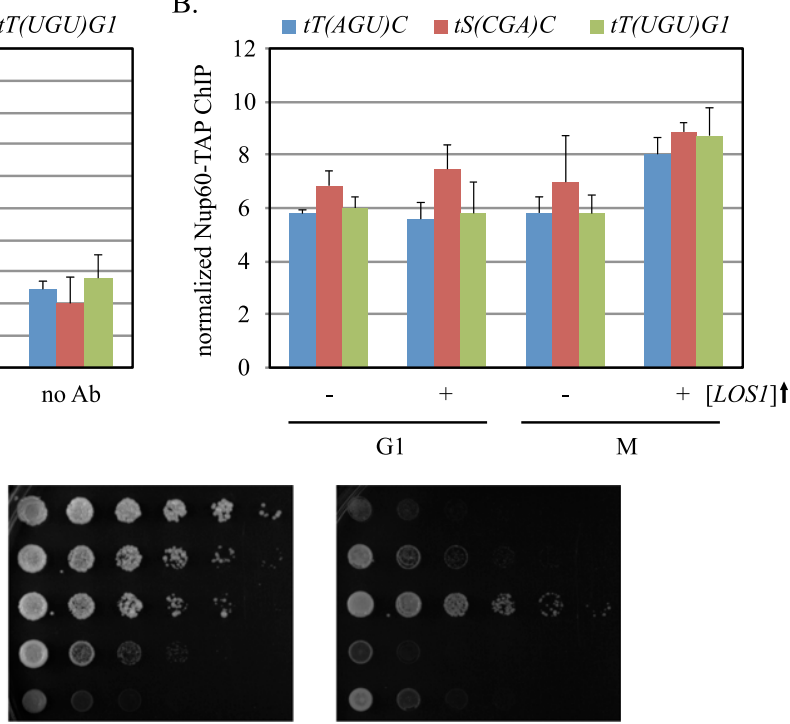

SC-ura,-ade

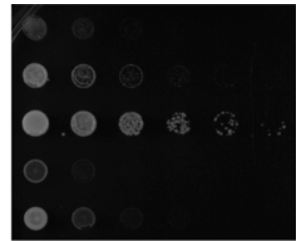

SC-ura, + EthGly

Figure 6. A role for LOS1 in NPC- $t D N A$ contact. $(A)$ Nup60 occupancy at $t D N A$ s. ChIP-qPCR of Nup60-TAP was performed with strains MC177 (wt), MC237 (Alos1), and MC253 (Amsn5) during M-phase arrest. Nup60-TAP binding was significantly diminished in the los1 mutant ( $P$-values are in Supplemental Table S4). (B) NPC- $t D N A$ contact with increased LOS1 dosage. ChIP-qPCR of Nup60TAP was performed with strain MC213 (Amaf1) transformed with either YEpFAT4-LOS1 or YEpFAT4. Strains were grown in SC-ura,met prior to arrest in M or G1. (C) Diminished nonsense suppression in the absence of NPC- $t D N A$ contact. Fivefold serial dilutions of strains W303-1A (wt), MC206 (Anup2), MC232 (4los1), K5824 (smc3-42), and K5832 (mcd1-73) bearing plasmid pUN60 were spotted on selective plates to measure activity of the plasmid-borne nonsense suppressor SUP11 ${ }^{\circ}$. (EthGly) $1.5 \mathrm{M}$ EthGly. To compensate for slower growth of strains $\mathrm{K} 5824$ and $\mathrm{K} 5832$ at $30^{\circ} \mathrm{C}$, the cultures were concentrated fivefold and 25 -fold, respectively, before diluting serially. Changes in growth of strains K5824 and K5832 in medium containing EthGly is not due to osmotic remediation of the cohesin mutations (Supplemental Fig. S5).

contact is limited by Los1, ChIP-qPCR was used to measure binding of Nup60 at $t D N A$ s in a strain bearing additional copies of a plasmid-borne LOS1 gene. To sensitize the assay, a maf1 mutant was used because elevated production of pre-tRNAs in this genetic background is known to exceed the capacity for their export (Karkusiewicz et al. 2011). During M-phase arrest, binding of Nup60-TAP to two representative tDNAs was significantly higher in cells with increased LOS1 gene dosage (Fig. 6B). Binding of Nup60-TAP to a third $t D N A$, $t S(C G A) C$, was also increased, but the significance was obscured by variability in the empty vector samples. Extra LOS1 did not increase binding in G1-arrested cells, consistent with the observation in Figure 5 that NPC contact is limited at this stage of the cell cycle by an upstream event; specifically, transcription by RNA polymerase III. Taken together, these experiments show not only that Los 1 promotes NPC-tDNA contact but that maximal contact in $M$ phase can be limited by the available pool of the exportin.

The LOS1 gene was originally cloned by virtue of its role in tRNA-mediated nonsense suppression: los $1 \mathrm{mu}-$ tants blocked suppression by hindering nuclear export of tRNA suppressors (Hopper et al. 1980; Hurt et al. 1987). We employed a pair of nonsense suppression assays to determine whether NPC- $t D N A$ contact was required for efficient pre-tRNA export. The first is based on an early observation that nonsense tRNA suppressors such as the
SUP11 ${ }^{\circ}$ ochre allele of the $t Y(G U A) F 1$ tDNA impart sensitivity to high osmolarity (Singh 1977). In the second assay, SUP $11^{\circ}$ suppresses the premature stop codon in ade2-1, thereby restoring adenine biosynthesis. In the presence of plasmid-borne $S U P 11^{\circ}$, a LOS1 ade2-1 strain grew well without exogenous adenine but poorly in the presence of a concentrated osmolyte, $1.5 \mathrm{M}$ ethylene glycol (EthGly) (Fig. 6C). Absence of LOS1, in contrast, hindered growth when adenine was omitted and improved growth in the presence of EthGly. Importantly, strains lacking NUP2 or bearing the cohesin mutations displayed phenotypes similar to the los 1 strain on the tester plates, albeit to different degrees. The combination of both positive and negative selections ensured that true suppression was not confused with the intrinsic growth behavior of each particular mutant. The simplest explanation is that NPC- $t D N A$ contact facilitates nonsense suppression, presumably by the export of the $S U P 11^{\circ}$ gene product.

\section{Discussion}

The central findings of this study are that (1) tDNAs migrate to NPCs as a consequence of increased transcription in $M$ phase; (2) association of $t D N A$ s with NPCs requires Los1, the pre-tRNA exportin; and (3) NPC- $t D N A$ contact contributes to nonsense suppression by a mutant tRNA. Taken together, these findings suggest 
that tRNA synthesis and nuclear export are coordinated events when $t D N A$ s localize at NPCs in yeast (Fig. 7).

Our results might seem at odds with an earlier report of $t D N A$ clustering at the nucleolus and a more recent report of $t D N A$ clustering with centromeres (Thompson et al. 2003; Duan et al. 2010). A parsimonious explanation would be that $t D N A$ s associate simultaneously with NPCs and either the nucleolus or centromeres at the edge of the nucleus. For the genes tested, however, NPC contact increased during $\mathrm{M}$ phase, whereas colocalization with the nucleolus remained low and constant throughout the cell cycle (Fig. 1). Similarly, colocalization of the genes with spindle pole bodies, where centromeres cluster at the nuclear membrane, was also rare (data not shown). If $t D N A$ s migrate to and from NPCs dynamically, transient positioning of individual genes outside the nucleolus or away from centromeres might have been missed with the technologies used earlier to monitor their positions.

\section{Potential advantages of tDNA transcription at NPCs}

Transcription of $t D N A$ s at NPCs might have evolved for several reasons. Foremost, NPC localization might expedite export of pre-tRNA, thereby avoiding an otherwise rate-limiting step in tRNA biogenesis. A corresponding advantage of accelerated export would be a decrease in the time that potentially deleterious pre-tRNAs spend in the nucleus. Mutations that increase the nuclear accumulation of mRNA, for example, pose a threat to genome stability by favoring the formation of R loops (Aguilera and Garcia-Muse 2012). According to this view, tRNAs that return to the nucleus must somehow evade R-loop formation.

tDNAs might also associate with NPCs to fine-tune tRNA production by means unrelated to export. For example, a recent study showed that Ulp1, an NPCassociated SUMO protease, accelerates derepression of the prototypical GAL1 gene, which migrates to NPCs during induction (Texari et al. 2013). This scenario and others in which $t D N A$ s associate with NPCs for reasons other than export are distinct because, in these cases, pretRNAs generated at the NPC might venture elsewhere in the nucleus before subsequent export.

\section{Los1 and the coordination of tRNA transcription and export}

The main argument for coordination between tRNA synthesis and export stems from the unexpected role for a pre-tRNA exportin in an upstream event in tRNA biogenesis; namely, docking of $t D N A$ s at NPCs. In gating of RNA polymerase II genes, the Mex67 export factor binds transcribed loci in an RNA-independent manner and then transfers to the assembling mRNP complex (Dieppois and Stutz 2010). How Los1 mediates NPCtDNA contact is not yet known. One model holds that the exportin bridges RNA polymerase III to NPCs directly. A less direct model, however, cannot be discounted: In the absence of Los1, accumulation of tRNA in the nucleus could trigger a regulatory response that releases all RNA polymerase III-transcribed genes from NPCs.

Coordinated transcription and nuclear export of pretRNA cannot be an essential function of the cell because mutants lacking NPC-tDNA contact are viable (Figs. 2, 6). We surmise that transcription of $t D N A$ s at NPCs facilitates export of pre-tRNAs that would eventually escape the nucleus by a less efficient process. Only when survival requires nonsense suppression can the defect in NPC- $t D N A$ contact be detected (Fig. 6C).

\section{Los1 versus Msn5 in the initial export of pre-tRNA}

Los 1 was defined as the principal exportin for intronbearing pre-tRNAs based on assays that monitored the
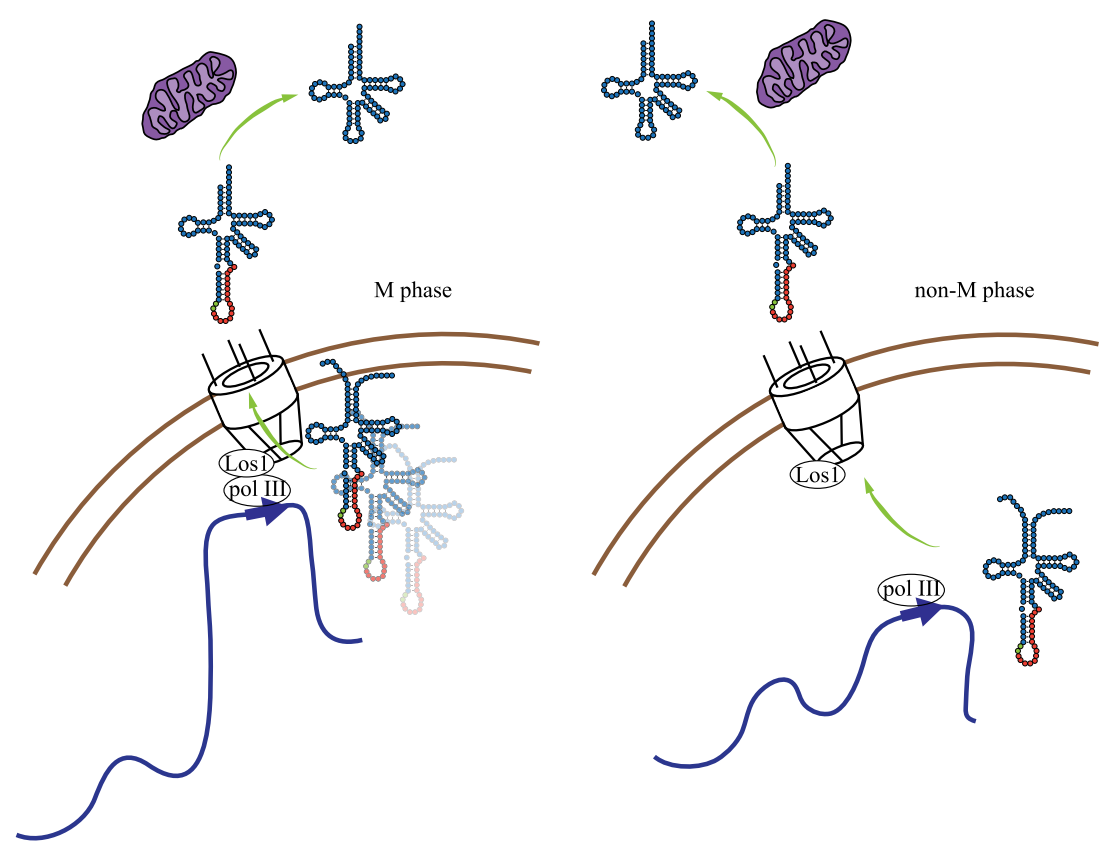

Figure 7. A model for coordinated transcription and export of pre-tRNAs from the nucleus. Increased transcription in $M$ phase by RNA polymerase III is accompanied by repositioning of $t D N A s$ at NPCs in a manner that depends on select Nups and the Los1 exportin. The model demands that nascent tRNAs mature at or near NPCs or that the transcripts synthesized at NPCs return to the nucleoplasm before export. Transcription outside of $\mathrm{M}$ phase when $t D N A$ s are not enriched at NPCs requires that pre-tRNA transit through the nucleoplasm before export. Pre-tRNAs that leave the nucleus are spliced on the cytoplasmic surface of mitochondria. 
fate of tRNA introns, which in yeast can only be spliced upon arrival in the cytoplasm (Hopper 2013). Due to the challenge of tracking the directional movement of tRNAs without introns, assigning the division of labor between LOS1 and MSN5 during the initial nuclear export phase has not been definitive. Our work now provides an unanticipated criterion for distinction. LOS1 alone mediates NPC- $t D N A$ contact (Fig. 6A,B). That the gene facilitates tethering of $t D N A$ s with introns as well as those without suggests that Los1 acts globally in the export of pre-tRNA. The results are consistent with Msn5 acting only on a subsequent step in tRNA trafficking, such as re-export.

\section{Spatial considerations of nuclear tRNA processing events}

Before exiting the nucleus, pre-tRNAs undergo significant processing. Most primary transcripts are trimmed, and numerous bases are modified chemically. Current thinking holds that sequential steps toward maturation occur at different locations in yeast (Hopper 2013). In order to reconcile this expectation with coordinated synthesis and export of tRNA at NPCs, two possibilities can be considered. First, pre-tRNAs synthesized at NPCs might venture back into the nuclear interior and to the sites of modification before subsequent export. Alternatively, tRNA processing events might actually occur at the NPC. A precedent for this scenario recently emerged from studies in Caenorhabditis elegans that showed that integral Nups of the NPC associate with numerous RNA polymerase III-transcribed genes to regulate $3^{\prime}$ end processing of the gene products (Ikegami and Lieb 2013). Based on these observations, the question of where tRNA modifications occur in the yeast nucleus warrants closer inspection.

\section{Cell cycle considerations of tDNA transcription}

Mature tRNAs are highly abundant and typically longlived, yet the gene products are produced periodically during the cell cycle (Figs. 3, 4; Supplemental Fig. S4). The logic behind such regulated synthesis might not be intuitive. Two recent discoveries provide conceptual frameworks for what might be occurring in budding yeast. First, a pair of research teams (Brickner and Brickner 2010; Bermejo et al. 2011) showed that gated RNA polymerase II-transcribed genes transiently release from NPCs during $S$ phase. Bermejo et al. (2011) argued that the process, which is regulated by the replication stress checkpoint pathway, avoids deleterious topological consequences of replicating immobilized DNA. Association of $t D N A s$ with NPCs might create a similar impediment to replication fork progression and thus might also be subject to a similar form of regulation. Second, Nguyen et al. (2010) showed that RNA polymerase III transcription is downregulated by the replication stress checkpoint during $S$ phase, presumably to avoid the deleterious consequences of blocked replication forks that accumulate at $t D N A \mathrm{~s}$ (Deshpande and Newlon 1996; Ivessa et al. 2003; Clelland and Schultz 2010; Szilard et al. 2010). Exactly how RNA polymerase III regulation occurs during normal proliferation in budding yeast and why attenuation also occurs in G1 prior to DNA replication will require further study.

\section{Materials and methods}

Strains and plasmids

Supplemental Table S1 lists the yeast strains used in this study. Complete ORF deletions and gene fusions were generated by PCR-mediated gene replacement and confirmed by PCR. Additional chromosome modifications were made with the integrating plasmids listed in Supplemental Table S2, as described in the Supplemental Material. nup133 deletions were covered with plasmids bearing either the full-length gene or the nup133- $\Delta \mathrm{N}$ allele (pNUP133-URA3 or pMC3, respectively).

\section{Cell growth}

Asynchronous cultures were grown to mid-log in SC medium. For M-phase arrest, Cdc20 was depleted from strains carrying MET3p-CDC20 by adding methionine $\left(\mathrm{C}_{\mathrm{f}}=2 \mathrm{mM}\right)$ to mid-log cultures pregrown in SC-met. Cells were harvested $2.5 \mathrm{~h}$ later after $\sim 80 \%-90 \%$ cells displayed a dumbbell-shaped morphology. For arrest with nocodazole $\left(\mathrm{C}_{\mathrm{f}}=10 \mu \mathrm{g} / \mathrm{mL}\right)$, cells were grown in YPDA. Cells were arrested in G1 with $\alpha$ factor $\left(C_{f}=1 \times 10^{-5} \mathrm{M}\right)$. To remove $\alpha$ factor, cells were washed twice and resuspended in medium containing pronase $\mathrm{E}\left(\mathrm{C}_{\mathrm{f}}=100 \mu \mathrm{g} / \mathrm{mL}\right)$. Flow cytometry was performed at the Rutgers Environmental and Occupational Health Sciences Institute (EOHSI) core facility. All experiments were performed at $30^{\circ} \mathrm{C}$ except the nonsense suppression assays in which strains were pregrown at $25^{\circ} \mathrm{C}$ in SC-ura before plating on selective medium at $30^{\circ} \mathrm{C}$.

\section{Microscopy}

Paraformaldehyde fixation, slide preparation, fluorescence microscopy, and error analysis were described previously (Chang et al. 2005). All data sets were based on at least three independent trials for a total of 100-300 cells per condition. Cell cycle stage was defined as follows: G1, no bud; S, small bud; and M, large bud with nucleus at the bud neck. Cells that had begun anaphase with single dots on either side of the bud neck were excluded from the analysis. Cohesin mutants yielded pairs of dots that were scored independently. GFP-tagged loci were defined as colocalized with an mRFP- or CFP-tagged protein if the fluorescent signals were separated by no more than the width of the GFP focus within the same or adjacent image planes.

\section{ChIP}

Cross-linking, extract preparation, and sonication were performed as in Ausubel et al. (2010). Subsequent procedures with anti-TAP antibody (Thermo Scientific) and protein A-coated Dynabeads (Life Technologies) were performed as in van Attikum et al. (2004). qPCR was performed with a Rotor-Gene Q (Qiagen) using the primers listed in Supplemental Table S3. Reported values correspond to the signal for each site relative to an internal control (GIT1) divided by the same ratio of sites within input. The mean and standard deviation of three or more biological replicates are presented. Statistical significance was determined by pairwise Student's $t$-tests.

\section{RNA analysis}

RNA was extracted with hot acidic phenol (Ausubel et al. 2010) and treated with DNase I (Roche). Reverse transcription was 
performed using SuperScript III First Strand Synthesis Supermix (Life Technologies) followed by qPCR using the primers listed in Supplemental Table S3. Values for each tRNA were normalized to an internal control (ACT1 mRNA) and are reported relative to the ratio in G1. The mean and standard deviation of three or more biological replicates are presented. Statistical significance was determined by pairwise Student's $t$-tests. Northern blots were hybridized with the $\gamma-{ }^{32} \mathrm{P}$-labeled oligonucleotides listed in Supplemental Table S3 according to Karkusiewicz et al. (2011) and were quantified with a Storm 840 PhosphorImager (Molecular Dynamics).

\section{Acknowledgments}

We thank Giulia Ruben, Rohinton Kamakaka, and Rudra Dubey for critical materials, discussion, and complementary experiments at the beginning of this study. We thank Eric Phizicky, Ian Willis, Rodney Rothstein, Andrés Aguilera, Chi Kwan Tsang, Nancy Woychik, and Steve Zheng for constructive criticism, technical advice, and materials. We thank Ruiheng Yin for expert experimental assistance, and Mike Hampsey for comments on the manuscript. This work was funded by National Institutes of Health grant R01GM51402.

\section{References}

Aguilera A, Garcia-Muse T. 2012. R loops: from transcription byproducts to threats to genome stability. Mol Cell 46: 115124.

Ausubel FM, Brent R, Kingston RE, Moore DD, Seidman JG, Smith JA, Struhl K, ed. 2010. Current protocols in molecular biology. John Wiley \& Sons, New York.

Bermejo R, Capra T, Jossen R, Colosio A, Frattini C, Carotenuto W, Cocito A, Doksani Y, Klein H, Gomez-Gonzalez B, et al. 2011. The replication checkpoint protects fork stability by releasing transcribed genes from nuclear pores. Cell 146: 233-246.

Bertrand E, Houser-Scott F, Kendall A, Singer RH, Engelke DR. 1998. Nucleolar localization of early tRNA processing. Genes Dev 12: 2463-2468.

Blobel G. 1985. Gene gating: a hypothesis. Proc Natl Acad Sci 82: 8527-8529.

Boguta M. 2013. Maf1, a general negative regulator of RNA polymerase III in yeast. Biochim Biophys Acta 1829: 376-384.

Bose T, Lee KK, Lu S, Xu B, Harris B, Slaughter B, Unruh J, Garrett A, McDowell W, Box A, et al. 2012. Cohesin proteins promote ribosomal RNA production and protein translation in yeast and human cells. PLoS Genet 8: e1002749.

Brickner DG, Brickner JH. 2010. Cdk phosphorylation of a nucleoporin controls localization of active genes through the cell cycle. Mol Biol Cell 21: 3421-3432.

Cabal GG, Genovesio A, Rodriguez-Navarro S, Zimmer C, Gadal O, Lesne A, Buc H, Feuerbach-Fournier F, Olivo-Marin JC, Hurt EC, et al. 2006. SAGA interacting factors confine sub-diffusion of transcribed genes to the nuclear envelope. Nature 441: 770-773.

Capelson M, Liang Y, Schulte R, Mair W, Wagner U, Hetzer MW. 2010. Chromatin-bound nuclear pore components regulate gene expression in higher eukaryotes. Cell 140: 372-383.

Casolari JM, Brown CR, Komili S, West J, Hieronymus H, Silver PA. 2004. Genome-wide localization of the nuclear transport machinery couples transcriptional status and nuclear organization. Cell 117: 427-439.

Chang CR, Wu CS, Hom Y, Gartenberg MR. 2005. Targeting of cohesin by transcriptionally silent chromatin. Genes Dev 19: 3031-3042.
Clelland BW, Schultz MC. 2010. Genome stability control by checkpoint regulation of tRNA gene transcription. Transcription 1: 115-125.

D'Ambrosio C, Schmidt CK, Katou Y, Kelly G, Itoh T, Shirahige K, Uhlmann F. 2008. Identification of cis-acting sites for condensin loading onto budding yeast chromosomes. Genes Dev 22: 2215-2227.

Denning D, Mykytka B, Allen NP, Huang L, Al B, Rexach M. 2001. The nucleoporin Nup60p functions as a Gsp1p-GTPsensitive tether for Nup2p at the nuclear pore complex. J Cell Biol 154: 937-950.

Deshpande AM, Newlon CS. 1996. DNA replication fork pause sites dependent on transcription. Science 272: 1030-1033.

Dieppois G, Stutz F. 2010. Connecting the transcription site to the nuclear pore: a multi-tether process that regulates gene expression. J Cell Sci 123: 1989-1999.

Dilworth DJ, Tackett AJ, Rogers RS, Yi EC, Christmas RH, Smith JJ, Siegel AF, Chait BT, Wozniak RW, Aitchison JD. 2005. The mobile nucleoporin Nup2p and chromatin-bound Prp20p function in endogenous NPC-mediated transcriptional control. J Cell Biol 171: 955-965.

Donze D, Kamakaka RT. 2001. RNA polymerase III and RNA polymerase II promoter complexes are heterochromatin barriers in Saccharomyces cerevisiae. EMBO J 20: 520-531.

Donze D, Adams CR, Rine J, Kamakaka RT. 1999. The boundaries of the silenced $H M R$ domain in Saccharomyces cerevisiae. Genes Dev 13: 698-708.

Doye V, Wepf R, Hurt EC. 1994. A novel nuclear pore protein Nup133p with distinct roles in poly(A)+ RNA transport and nuclear pore distribution. EMBO J 13: 6062-6075.

Duan Z, Andronescu M, Schutz K, Mcllwain S, Kim YJ, Lee C, Shendure J, Fields S, Blau CA, Noble WS. 2010. A threedimensional model of the yeast genome. Nature 465: 363367.

Dubey RN, Gartenberg MR. 2007. A tDNA establishes cohesion of a neighboring silent chromatin domain. Genes Dev 21: 2150-2160.

Egecioglu D, Brickner JH. 2011. Gene positioning and expression. Curr Opin Cell Biol 23: 338-345.

Gard S, Light W, Xiong B, Bose T, McNairn AJ, Harris B, Fleharty B, Seidel C, Brickner JH, Gerton JL. 2009. Cohesinopathy mutations disrupt the subnuclear organization of chromatin. J Cell Biol 187: 455-462.

Gartenberg MR, Neumann FN, Laroche T, Blaszczyk M, Gasser SM. 2004. Sir-mediated repression can occur independently of chromosomal and subnuclear contexts. Cell 119: 955-967.

Gottesfeld JM, Forbes DJ. 1997. Mitotic repression of the transcriptional machinery. Trends Biochem Sci 22: 197-202.

Haeusler RA, Engelke DR. 2006. Spatial organization of transcription by RNA polymerase III. Nucleic Acids Res 34: 4826-4836.

Haeusler RA, Pratt-Hyatt M, Good PD, Gipson TA, Engelke DR. 2008. Clustering of yeast tRNA genes is mediated by specific association of condensin with tRNA gene transcription complexes. Genes Dev 22: 2204-2214.

Hampsey M, Singh BN, Ansari A, Laine JP, Krishnamurthy S. 2011. Control of eukaryotic gene expression: gene loops and transcriptional memory. Adv Enzyme Regul 15: 118-125.

Hellmuth K, Lau DM, Bischoff FR, Kunzler M, Hurt E, Simos G. 1998. Yeast Los1p has properties of an exportin-like nucleocytoplasmic transport factor for tRNA. Mol Cell Biol 18: 6374-6386.

Hiraga S, Botsios S, Donze D, Donaldson AD. 2012. TFIIIC localizes budding yeast ETC sites to the nuclear periphery. Mol Biol Cell 23: 2741-2754. 
Hopper AK. 2013. Transfer RNA post-transcriptional processing, turnover, and subcellular dynamics in the yeast Saccharomyces cerevisiae. Genetics 194: 43-67.

Hopper AK, Schultz LD, Shapiro RA. 1980. Processing of intervening sequences: a new yeast mutant which fails to excise intervening sequences from precursor tRNAs. Cell 19: 741-751.

Hurt DJ, Wang SS, Lin YH, Hopper AK. 1987. Cloning and characterization of LOS1, a Saccharomyces cerevisiae gene that affects tRNA splicing. Mol Cell Biol 7: 12081216.

Ikegami K, Lieb JD. 2013. Integral nuclear pore proteins bind to Pol III-transcribed genes and are required for Pol III transcript processing in C. elegans. Mol Cell 51: 840-849.

Ivessa AS, Lenzmeier BA, Bessler JB, Goudsouzian LK, Schnakenberg SL, Zakian VA. 2003. The Saccharomyces cerevisiae helicase Rrm3p facilitates replication past nonhistone protein-DNA complexes. Mol Cell 12: 1525-1536.

Iwasaki O, Tanaka A, Tanizawa H, Grewal SI, Noma K. 2010. Centromeric localization of dispersed Pol III genes in fission yeast. Mol Biol Cell 21: 254-265.

Kalverda B, Pickersgill H, Shloma VV, Fornerod M. 2010. Nucleoporins directly stimulate expression of developmental and cell-cycle genes inside the nucleoplasm. Cell 140: 360-371.

Karkusiewicz I, Turowski TW, Graczyk D, Towpik J, Dhungel N, Hopper AK, Boguta M. 2011. Maf1 protein, repressor of RNA polymerase III, indirectly affects tRNA processing. J Biol Chem 286: 39478-39488.

Kirkland JG, Raab JR, Kamakaka RT. 2013. TFIIIC bound DNA elements in nuclear organization and insulation. Biochim Biophys Acta 1829: 418-424.

Kobayashi T, Horiuchi T, Tongaonkar P, Vu L, Nomura M. 2004. SIR2 regulates recombination between different $r D N A$ repeats, but not recombination within individual rRNA genes in yeast. Cell 117: 441-453.

Menon BB, Sarma NJ, Pasula S, Deminoff SI, Willis KA, Barbara KE, Andrews B, Santangelo GM. 2005. Reverse recruitment: the Nup84 nuclear pore subcomplex mediates Rap1/Gcr1/ Gcr2 transcriptional activation. Proc Natl Acad Sci 102: 5749-5754.

Murthi A, Shaheen HH, Huang HY, Preston MA, Lai TP, Phizicky EM, Hopper AK. 2010. Regulation of tRNA bidirectional nuclear-cytoplasmic trafficking in Saccharomyces cerevisiae. Mol Biol Cell 21: 639-649.

Nguyen VC, Clelland BW, Hockman DJ, Kujat-Choy SL, Mewhort HE, Schultz MC. 2010. Replication stress checkpoint signaling controls tRNA gene transcription. Nat Struct Mol Biol 17: 976-981.

Noma K, Cam HP, Maraia RJ, Grewal SI. 2006. A role for TFIIIC transcription factor complex in genome organization. Cell 125: 859-872.

Oeffinger M, Zenklusen D. 2012. To the pore and through the pore: a story of mRNA export kinetics. Biochim Biophys Acta 1819: 494-506.

Roberts DN, Wilson B, Huff JT, Stewart AJ, Cairns BR. 2006. Dephosphorylation and genome-wide association of Maf1 with Pol III-transcribed genes during repression. Mol Cell 22: 633-644.

Ruben GJ, Kirkland JG, Macdonough T, Chen M, Dubey RN, Gartenberg MR, Kamakaka RT. 2011. Nucleoporin mediated nuclear positioning and silencing of HMR. PLOS ONE 6: e21923.

Sarkar S, Hopper AK. 1998. tRNA nuclear export in Saccharomyces cerevisiae: in situ hybridization analysis. Mol Biol Cell 9: 3041-3055.
Schmid M, Arib G, Laemmli C, Nishikawa J, Durussel T, Laemmli UK. 2006. Nup-PI: the nucleopore-promoter interaction of genes in yeast. Mol Cell 21: 379-391.

Shaheen HH, Hopper AK. 2005. Retrograde movement of tRNAs from the cytoplasm to the nucleus in Saccharomyces cerevisiae. Proc Natl Acad Sci 102: 11290-11295.

Singh A. 1977. Nonsense suppressors of yeast cause osmoticsensitive growth. Proc Natl Acad Sci 74: 305-309.

Szilard RK, Jacques PE, Laramee L, Cheng B, Galicia S, Bataille AR, Yeung M, Mendez M, Bergeron M, Robert F, et al. 2010. Systematic identification of fragile sites via genome-wide location analysis of $\gamma$-H2AX. Nat Struct Mol Biol 17: 299305.

Taddei A, Gasser SM. 2012. Structure and function in the budding yeast nucleus. Genetics 192: 107-129.

Takano A, Endo T, Yoshihisa T. 2005. tRNA actively shuttles between the nucleus and cytosol in yeast. Science 309: 140142.

Texari L, Dieppois G, Vinciguerra P, Contreras MP, Groner A, Letourneau A, Stutz F. 2013. The nuclear pore regulates GAL1 gene transcription by controlling the localization of the SUMO protease Ulp1. Mol Cell 51: 807-818.

Thompson M, Haeusler RA, Good PD, Engelke DR. 2003. Nucleolar clustering of dispersed tRNA genes. Science 302: 1399-1401.

Valenzuela L, Dhillon N, Dubey RN, Gartenberg MR, Kamakaka RT. 2008. Long-range communication between the silencers of HMR. Mol Cell Biol 28: 1924-1935.

van Attikum H, Fritsch O, Hohn B, Gasser SM. 2004. Recruitment of the INO80 complex by H2A phosphorylation links ATP-dependent chromatin remodeling with DNA double-strand break repair. Cell 119: 777-788.

Yoshihisa T, Yunoki-Esaki K, Ohshima C, Tanaka N, Endo T. 2003. Possibility of cytoplasmic pre-tRNA splicing: the yeast tRNA splicing endonuclease mainly localizes on the mitochondria. Mol Biol Cell 14: 3266-3279. 


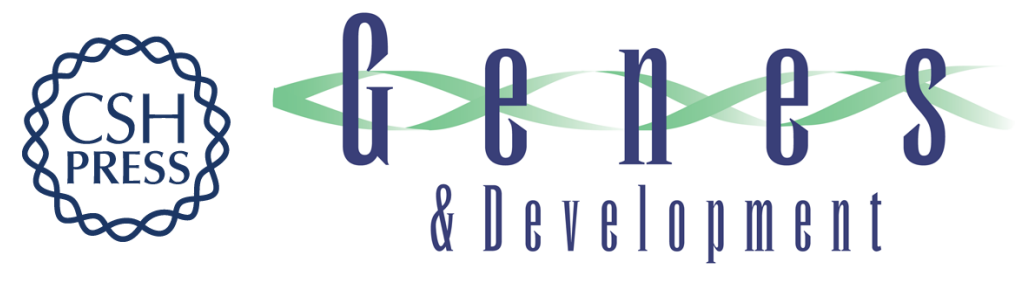

\title{
Coordination of tRNA transcription with export at nuclear pore complexes in budding yeast
}

\author{
Miao Chen and Marc R. Gartenberg
}

Genes Dev. 2014, 28:

Access the most recent version at doi:10.1101/gad.236729.113

\section{Supplemental http://genesdev.cshlp.org/content/suppl/2014/04/29/28.9.959.DC1 Material}

References

This article cites 60 articles, 30 of which can be accessed free at: http://genesdev.cshlp.org/content/28/9/959.full.html\#ref-list-1

Creative This article is distributed exclusively by Cold Spring Harbor Laboratory Press for the first Commons six months after the full-issue publication date (see

License http://genesdev.cshlp.org/site/misc/terms.xhtml). After six months, it is available under a Creative Commons License (Attribution-NonCommercial 4.0 International), as described at http://creativecommons.org/licenses/by-nc/4.0/.

Email Alerting Receive free email alerts when new articles cite this article - sign up in the box at the top Service right corner of the article or click here.

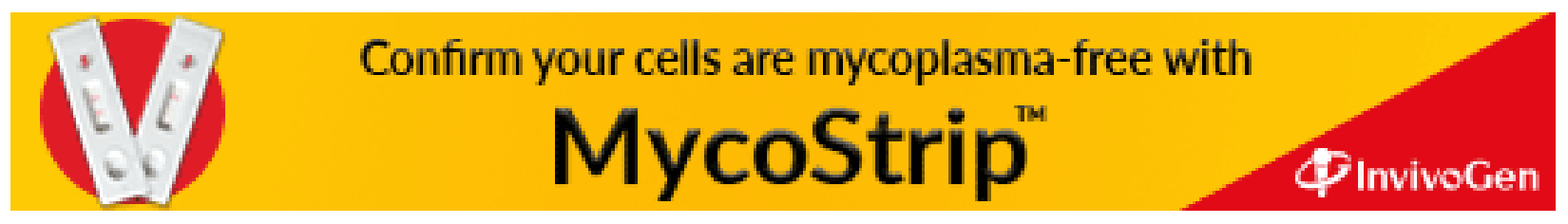

